\title{
Effect of Fiber Weight Ratio and Fiber Modification on Flexural Properties of Posidonia-Polyester Composites
}

\author{
S. Zannen' ${ }^{1}$ L. Ghali' ${ }^{1}$, M. T. Halimi ${ }^{1}$, M. Ben Hassen ${ }^{1,2}$ \\ ${ }^{1}$ Textile Engineering Laboratory, Monastir University, Monastir, Tunisia \\ ${ }^{2}$ Industrial Engineering Department, College of Engineering, Taiba University, Medina, Saudi Arabia \\ Email: saoussenzannen@hotmail.fr
}

Received 30 March 2016; accepted 28 June 2016; published 1 July 2016

Copyright (C) 2016 by authors and Scientific Research Publishing Inc.

This work is licensed under the Creative Commons Attribution International License (CC BY). http://creativecommons.org/licenses/by/4.0/

c) (i) Open Access

\section{Abstract}

The main objective of this research is to study the effect of fiber weight ratio and chemical fiber modification on flexural properties of composites reinforced with Posidonia fiber. An unsaturated polyester matrix reinforced with untreated and treated Posidonia fibers was fabricated under various fiber weight ratios. Results showed that the combined chemical treatment provided better mechanical properties of composites in comparison with untreated fiber. The fiber weight ratio influenced the flexural properties of composites. Indeed, a maximum value of flexural modulus was observed for $10 \%$ fiber weight ratio for composites reinforced with treated fibers. SEM photographs revealed a different fracture surface between Posidonia fibers reinforced polyester composites.

\section{Keywords}

Composites, Posidonia Fiber, Weight Ratio, Flexural Modulus, Flexural Strength, Elongation, SEM Micrographs

\section{Introduction}

Natural fibre-reinforced polymer composites have gained attention among materials scientists and engineers in recent years due to the need to develop an environmental friendly material and partly replace currently used synthetic fibres in fibre-reinforced composites. The benefits of natural fibre composites include high specific strength and modulus, low cost, light weight, biodegradability and recyclability. Therefore, natural fibre-based composites have good potential for use as structural materials. Several authors have reported the use of natural 
fibres such as sisal, banana, henequen, jute, hemp and wood pulpas reinforcements in polymer matrixes [1]-[7].

Many chemical treatments such as sodium hydroxide, silane, acetic acid, acrylic acid, maleated coupling agents, isocyanates, potassium permanganate, peroxide, etc., were widely used for modification of fiber surface [8]. Moreover, several researches show a significant influence of these chemical treatments on physical, chemical and mechanical properties of natural fibres as well as on the properties of fiber-polymer composites [9]-[12].

Posidonia oceanic is a species of seagrass that is endemic to the Mediterranean Sea. This marine plant loses leaves in autumn, and the cast litter deposits can be found mainly along sandy coasts, forming wedge structures, from a few centimetres to several meters thick, denominated "banquettes". In the Mediterranean region, where summer tourism is an important income, the "banquette" is often removed because it is believed to reduce the value of beaches and every summer the beaches must be cleaned. The valorization of this available biomass can be the solution of that problem [13] [14]. On the other hand, environmental concerns have led to an increased demand for renewable materials in many industrial applications. Then, this aquatic biomass represents an abundant, inexpensive, and readily available source of renewable lignocellulosic biomass for the production of environmentally friendly industrial products and has received increasing attention. In the last few years, Posidonia oceanic has been studied as: (1) a low-cost adsorbent for removing dyes or phenol [15], (2) a substrate for papermaking [16], (3) a starting material for cellulose derivatives [14], (4) a reinforcement on composites [17]. However, to the best of our knowledge, no data has been reported yet regarding the chemical treatment of these materials in order to improve their morphological and mechanical properties as fillers in composite materials.

There for the aim of this study is to explain the variations of the flexural proprieties of the composites Posidonia - unsaturated polyester matrix with those of fibers weight ratio and combined chemical treatment of Posidonia fibers.

\section{Materials and Methods}

\subsection{Fibers and Composites Preparation}

The balls of Posidonia are collected from Hergla's beach in Tunisia. It was manually frayed and placed on a horizontal opener. The balls opened manually are driven by a rolling lurking and then they are engaged in a threshing cylinder. Subsequently, they are driven by means of a toothed roller in order to separate fibers. By centrifugal force and aspiration the good fibers are driven upwardly and the waste falls down. After this mechanical treatment we obtain the fibers shown in Figure 1 and considered as raw fibers.

Then, in order to improve the adhesion fiber-composite, the raw Posidonia fibers surface was modified using a combined chemical treatment: sodium hydroxide and hydrogen peroxide.

For the combined chemical treatment, raw Posidonia fiber was treated using a Datacolor AHIBA MSTRI. Then, $5 \mathrm{~g}$ of raw Posidonia fibers were immersed in a bath with a Liquor ratio of 1 by 40 . This bath contains 25 $\mathrm{ml} / \mathrm{L}$ of Hydrogen peroxide and $20 \mathrm{~g} / \mathrm{l}$ of Sodium hydroxide. The whole mixture has been taken to temperature of $100^{\circ} \mathrm{C}$ under agitation and pressure during $45 \mathrm{~min}$. The treated fibers were thoroughly rinsed with water several times and there are dried to the ambient air for $48 \mathrm{~h}$.

The treated and untreated fibers were characterized by means of physical and mechanical analysis in order to define their properties. The tests must carry out on a batch of conditioned fibers to a normal atmosphere (relative humidity: $65 \% \pm 4 \%$, temperature: $20^{\circ} \mathrm{C} \pm 2{ }^{\circ} \mathrm{C}$ ).

The Posidonia fibers were used to reinforce an unsaturated polyester matrix. The composites were manufactured manually by placing fibers and resin inside a glass mould. In order to remove en-trapped air bubbles and

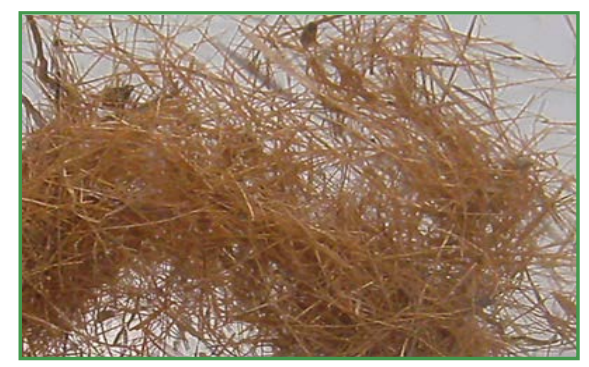

Figure 1. Posidonia fibers. 
also enabled manufacturing all uniform thickness composites, the mould was closed and pressed. Three percentages by weight of fibrous reinforcement (raw and treated fibers) were made: $5 \%, 10 \%$ and $15 \%$.

\subsection{Flexural Test}

After composite material preparation, test samples were cutted from composite panel to use in the mechanical characterization with the three-point bending flexure test according to the standard EN ISO 14125 (1998).

The flexural properties of pur-polyester samples and polyester reinforced by Posidonia fibers were made using a universal testing machine LLOYD. A speed of $5 \mathrm{~mm} / \mathrm{min}$ and a measurement cell of $5 \mathrm{KN}$ were used. The values were reported as averages of 10 test replicates

The flexural strength $(\sigma)$, the flexural modulus $(E)$ and the surface elongation at break $(\varepsilon)$ are calculated respectively by:

$$
\begin{aligned}
& \text { Flexural Strength } \sigma=\frac{3 F L}{2 b h^{2}} \text { Equation (1) } \\
& \text { Flexural Modulus } E=\frac{L^{3} F}{4 b h^{3} w} \text { Equation (2) } \\
& \text { Elongation at Break } \varepsilon=\frac{6 w h}{L^{2}} \text { Equation (3) }
\end{aligned}
$$

where $F$ is the maximum load $(\mathrm{N}), L$ is the range $(\mathrm{mm}), h$ is the specimen thickness $(\mathrm{mm}), b$ is the specimen width (mm) and $w$ indicates the defection (mm).

\subsection{Scannig Electron Microscopy}

To observe the surface topography and shrieking surface of composites, Scanning Electron Microscopy (SEM, HITACHI TM 3000) was then used at low and high magnification. The metallized specimens were analyzed in partial vacuum conditions ( 0.1 - 0.15 torr), and under an accelerating voltage ranging from 10 to $15 \mathrm{KV}$.

\section{Results and Discussions}

\subsection{Fiber Characterization}

The mechanical and physical properties of raw and treated Posidonia fibers are presented in Table 1.

It is clear that the physical and mechanical properties were influenced after the chemical treatment. In fact, the fibers linear density decreases after this combined chemical treatment. This reduce of mass per unit of length could be attributed to the removal of waxy and gummy substances cross linking the ultimate fibers. Also the treated Posidonia fibers present a lower diameter than those untreated. This decrease in fiber diameter could be attributed to the influence of combined chemical treatment. Besides there is a decrease in fibres tenacity and elongation after combined chemical treatment (hydrogen peroxide and sodium hydroxide). This decrease attributed to the substantial delignification and degradation of cellulosic chains during chemical treatment.

Hence, change of the physical properties form depends strongly on the treatment of the fiber. It is important to indicate that good cohesion between fibers and matrix is assured by many parameters such as the surface area, the roughness and the surface tensile of fibers [18] [19].

\subsection{Effect of Fiber Treatment on Flexural Properties of Composites}

The realization of composite materials requires the use of a matrix and reinforcement. In this case, we test the potential of using Posidonia fibers as reinforcement with a polyester matrix.

Table 1. Physical and mechanical properties of Posidonia fibers.

\begin{tabular}{cccc}
\hline & Diameter $(\boldsymbol{\mu m})$ & Linear Density (tex) & Tenacity (cN/tex) \\
\hline Raw Posidonia Fibers (RPF) & $165.56 \pm 7.45$ & $9.31 \pm 0.36$ & $11.19 \pm 0.39$ \\
Treated Posidonia Fibers (TPF) & $136.42 \pm 4.84$ & $7.24 \pm 0.27$ & $8.2 \pm 0.26$ \\
\hline
\end{tabular}


The three point bending flexure tests were carried out on pure polyester specimen (Comp PES), polyester reinforced by raw Posidonia fibers and polyester reinforced treated Posidonia fibers.

Figure 2 shows the shape of the PES bending curves and PES/Posidonia fibers. It is noted from this figure that the failure mechanism for the single polymer is the same of the composite. The curve was clearly linear for the PES and Posidonia fibers reinforced polyester composites. Besides, the flexural properties increase with the addition of fibers.

Table 2 shows the results of three points bending flexural test of polyester matrix reinforced with the mixture of treated and untreated Posidonia fibers of a weight ratio of $10 \%$ of fibrous reinforcement.

According to this table, it can be noted that the reinforcement of polyester matrix with Posidonia fibers changes the flexural properties of composite material. Indeed, whatever the nature of the fiber reinforcement (raw or treated) added to the matrix, the modulus of elasticity has an increase. Thus, the rate of increase of this mechanical parameter is about $52.9 \%$ for the raw Posidonia fibers and $90.5 \%$ for the treated Posidonia fibers compared to pure polyester. This affirms well the trend widely illustrated in the literature: improving the mechanical response of the system after aggregation reinforcements in polymer matrices [20] [21]. Also we can notice that the flexural modulus and stress of composites reinforced with treated fibers is more important compared with those of untreated fibers. This increase of mechanical properties could be explained by the good adhesion between fiber and matrix. Then, the combined chemical treatment has enhanced the bonding between fiber and polymer tanks to the increase of the number of possible reaction sites ( $\mathrm{OH}$ and $\mathrm{CH}$ groups) when increasing the cellulose amount exposed on the fiber surface. In fact, this could be proved by the broad band observed at 3000 $3500 \mathrm{~cm}^{-1}$ in the spectra (Figure 3) indicating the presence of $\mathrm{OH}$ group. Moreover, the second band was observed at $2857-2926 \mathrm{~cm}^{-1}$ indicating the stretching vibration of the groups $-\mathrm{CH}$ and $-\mathrm{CH}_{2}$ of cellulose and another band at $1450 \mathrm{~cm}^{-1}$, which also indicates the presence of - $\mathrm{CH}$ produced by a symmetrical deformation of lignin and alpha cellulose. Furthermore, the ratio of the intensities of the transmittance peaks at $3343 \mathrm{~cm}^{-1}(-\mathrm{OH})$

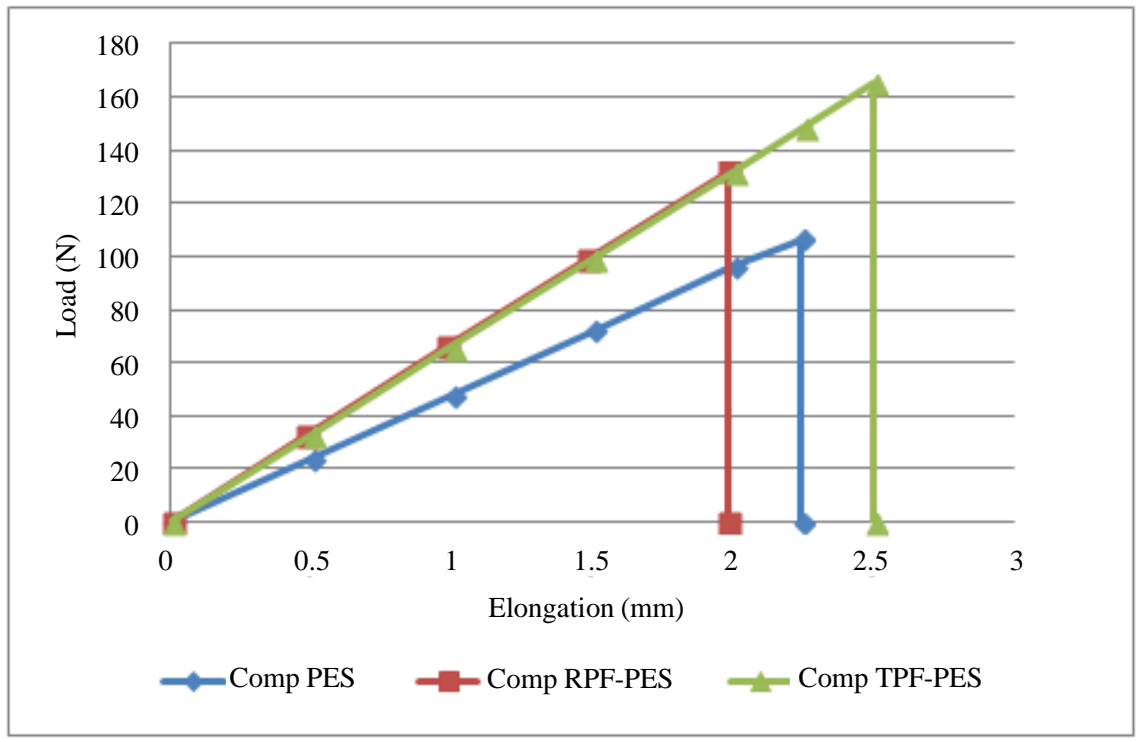

Figure 2. Curves three points bending tests of the pur-polyester (Comp PES), composites of untreated Posidonia fibers-PES (Comp RPF-PES) and composites of treated Posidonia fibers-PES (Comp TPF-PES).

Table 2. Flexural properties of polyester composites reinforced by Posidonia fibers.

\begin{tabular}{cccc}
\hline Specimen & $\begin{array}{c}\text { Fiber Weigth Ratio } \\
(\mathbf{\%})\end{array}$ & E (GPa) & $\boldsymbol{\sigma}(\mathbf{M P a})$ \\
\hline Comp TPF-PES & 10 & $4.61 \pm 0.35$ & $34.7 \pm 5.05$ \\
Comp RPF-PES & 10 & $3.7 \pm 0.24$ & $31.68 \pm 5,18$ \\
Comp PES & 0 & $2.42 \pm 0.65$ & $28.8 \pm 3.84$ \\
\hline
\end{tabular}




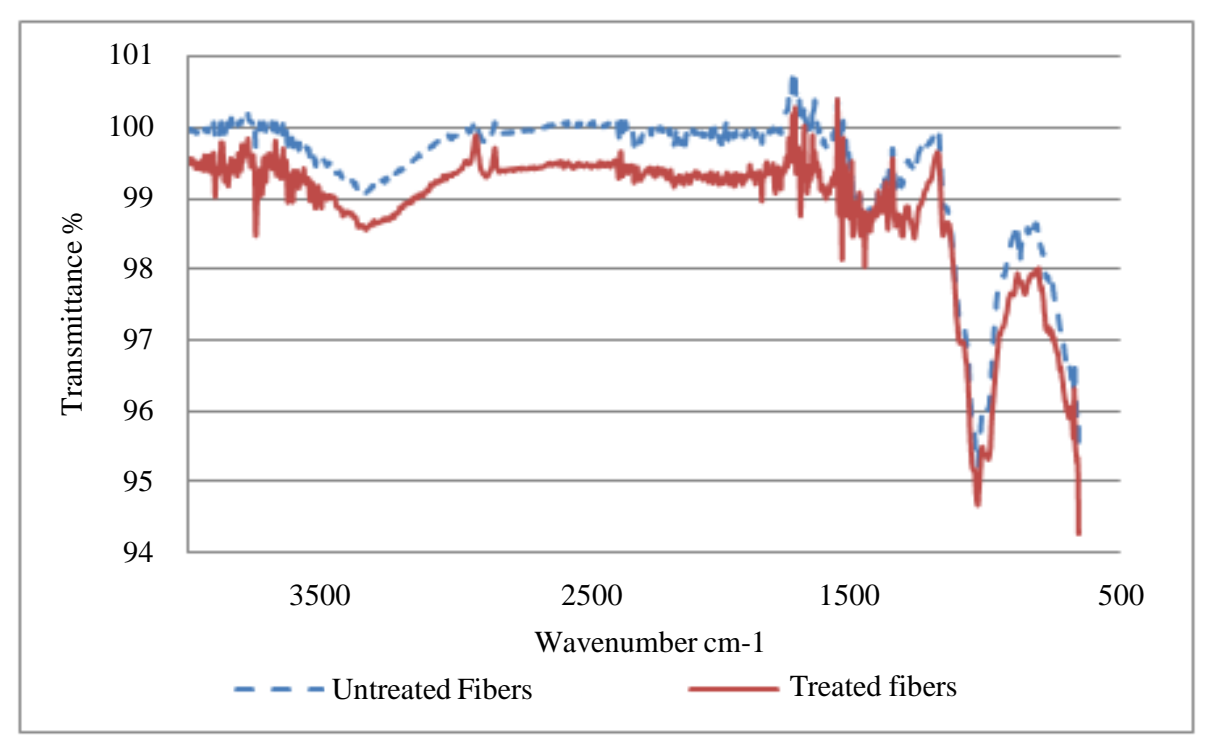

Figure 3. FT-IR spectra of untreated and treated Posidonia fibers.

and $2900 \mathrm{~cm}^{-1}\left(>\mathrm{CH}_{2},>\mathrm{CH}-\right)$ for the raw (0.9937); (0.9985) and treated (0.985); (0.994) fibers indicated the presence of more $-\mathrm{OH}$ groups in the treated fiber than in the virgin sample.

It is noted also, that the tenacity increases upon the addition of the reinforcement while the elongation decreases. Which means that the composite become more resistant but less deformable and this can be explained by the fact that adding fibers to the matrix let the bending load shared throughout all the composite including fibers that oppose bending to improve the load supported by the composite while blocking structure which reduces deformation.

The SEM micrographs of the fracture surface of composite specimens reinforced with treated and untreated Posidonia fibers presented in Figure 4 showed that adhesion between fiber and matrix enhances with the chemical treatments. In fact, as shown in Figure 4(a1), before modification, the wettability between Posidoniafibers and unsaturated polyester matrix seemed to be poor because of the presence of a gap between the two componements. This gap is much less visible in the case were the fibers were treated with combined process (Figure 4 (a2) and Figure 4(b2)). Alsowe can remark that the matrix surrounding the fibers led to a good adhesion. This result confirmed the enhancement of mechanical properties of composite reinforced with treated fibers. Thus, when the Posidonia fibers were treated with sodium hydroxide and hydrogen peroxide, the gap is much less pronounced and an improved interface corroborated well the enhancement of the previously mechanical properties observed in Table 2.

\subsection{Effect of Fiber Weight Ratio on Flexural Properties of Composites}

Whatever the nature of the fiber reinforcement (raw or treated) added to the polymer matrix, it is evident that the flexural modulus and strength increases when increasing content fiber. In fact, the polyester resin transmits and distributes the applied stress to the Posidonia fibers resulting in higher flexural modulus and strength. As result, the composite can sustain higher load before failure compared to the unreinforced polyester.

In fact, the flexural modulus increases when increasing weight ratio of raw fibers. However, for the treated fibers the modulus achieved a threshold of $4.61 \mathrm{Gpa}$ at a fiber weight ratio of $10 \%$.Then the flexural modulus is almost doubled compared to that of single matrix. As well as, exceeding this percentage of reinforcing we notice a reduction in this property (4.21 Gpa for a treated-fiber weight ratio of 15\%). This decrease can be explained by the poor cohesion between fibrous reinforcement and matrix by increasing the fiber weight ratio (Figure 5).

We can also indicate that the addition of fiber reinforcement (raw or processed) increases the flexural strength of the material. This increase is significant in the case of the treated fibers. This can be explained by the fact that the treatment has improved adhesion between fiber-matrix. This constraint is very important in the case of reinforcement with a rate of $15 \%$ for the treated and untreated fibers.

However these tests demonstrate that the addition of fibers decreases the deformation at break of reinforced 

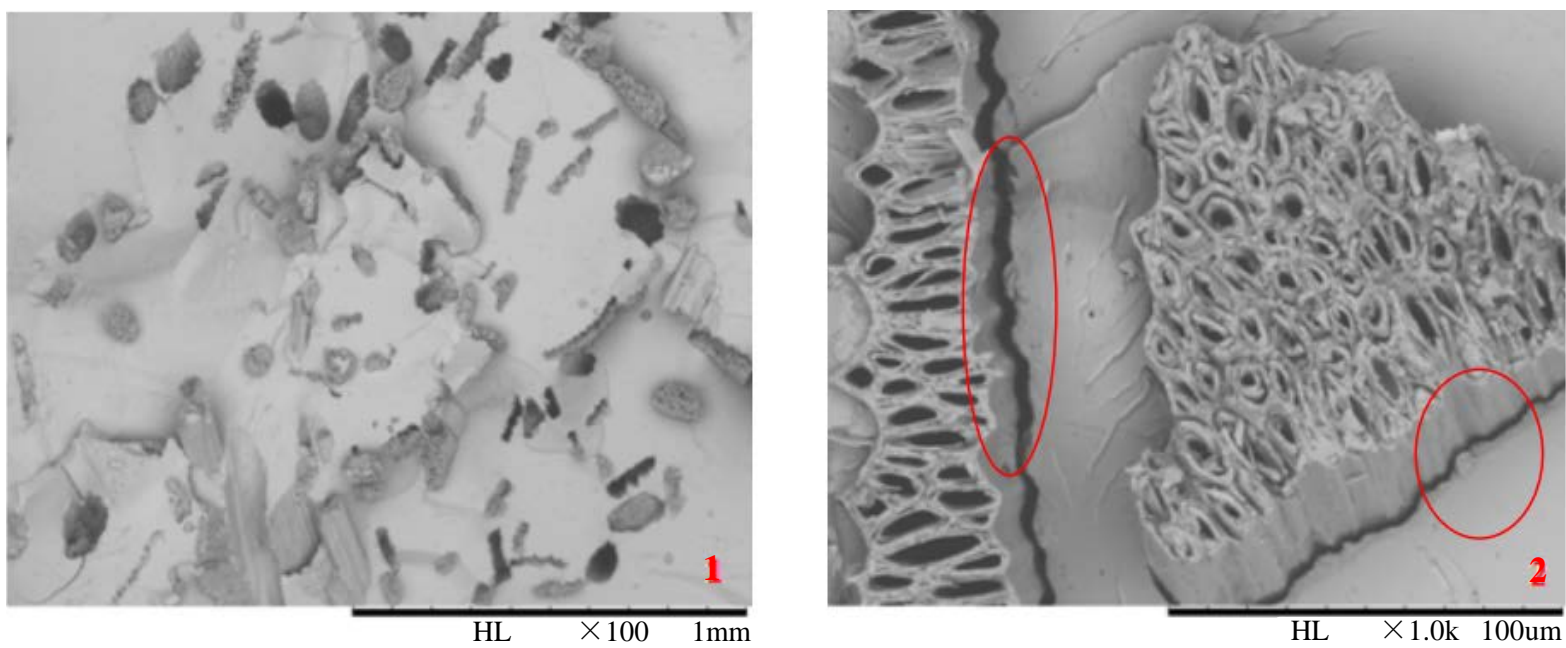

(a)
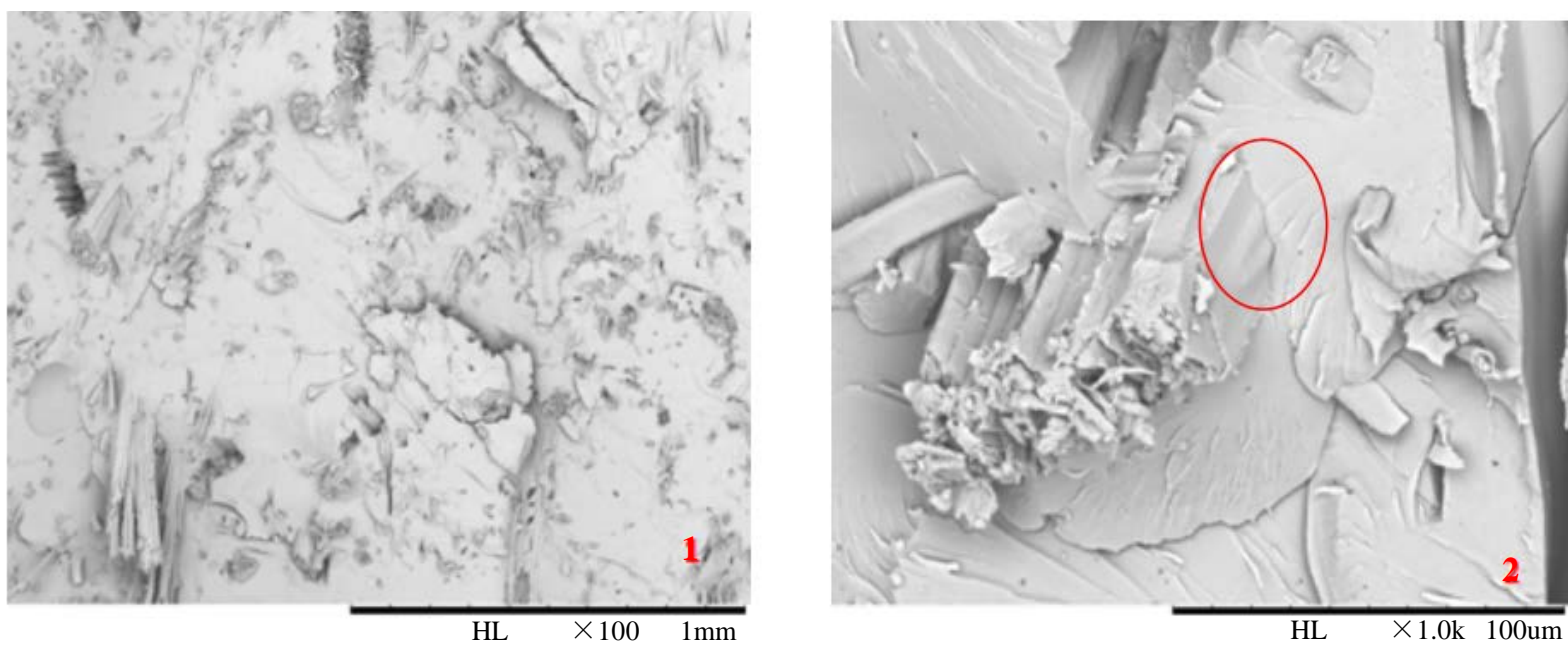

(b)

Figure 4. SEM micrographs of fracture surface of: (a) composites reinforced with untreated fiber, (b) composite reinforced with treated fiber.

composites compared to those non-reinforced. This decrease can be explained by the rigidity of the materials following the reduction of the free volume in the matrix alone. Also we can notice that the elongation at break is more important in the case of treated fibers with a fiber weight ratio of $10 \%$ and $15 \%$ compared to non-treated fibers.

\section{Conclusions}

In this study, the influence of the fiber's combined chemical treatment on the flexural proprieties of Posidonia polyester composite was investigated. The variation of these properties with the rise of fiber weight ratio was also studied.

Results prove that all flexural properties are enhanced expect elongation which means the adding of fiber in the polyester matrix to make the composite more resistant but less deformable. In fact, there was an increase in flexural modulus and strength of reinforced composites. The best flexural modulus (4.61 Gpa) was obtained in the case of composites reinforced with treated fibers with a weight ratio of $10 \%$. The elongation at break of composites reinforced with treated fibers is more important compared with those of non-treated. Then, the mechanical properties were enhanced when reinforcing composites with treated fibers.

Then results presented in this work indicate that it is possible to enhance the properties of fiber-reinforced 

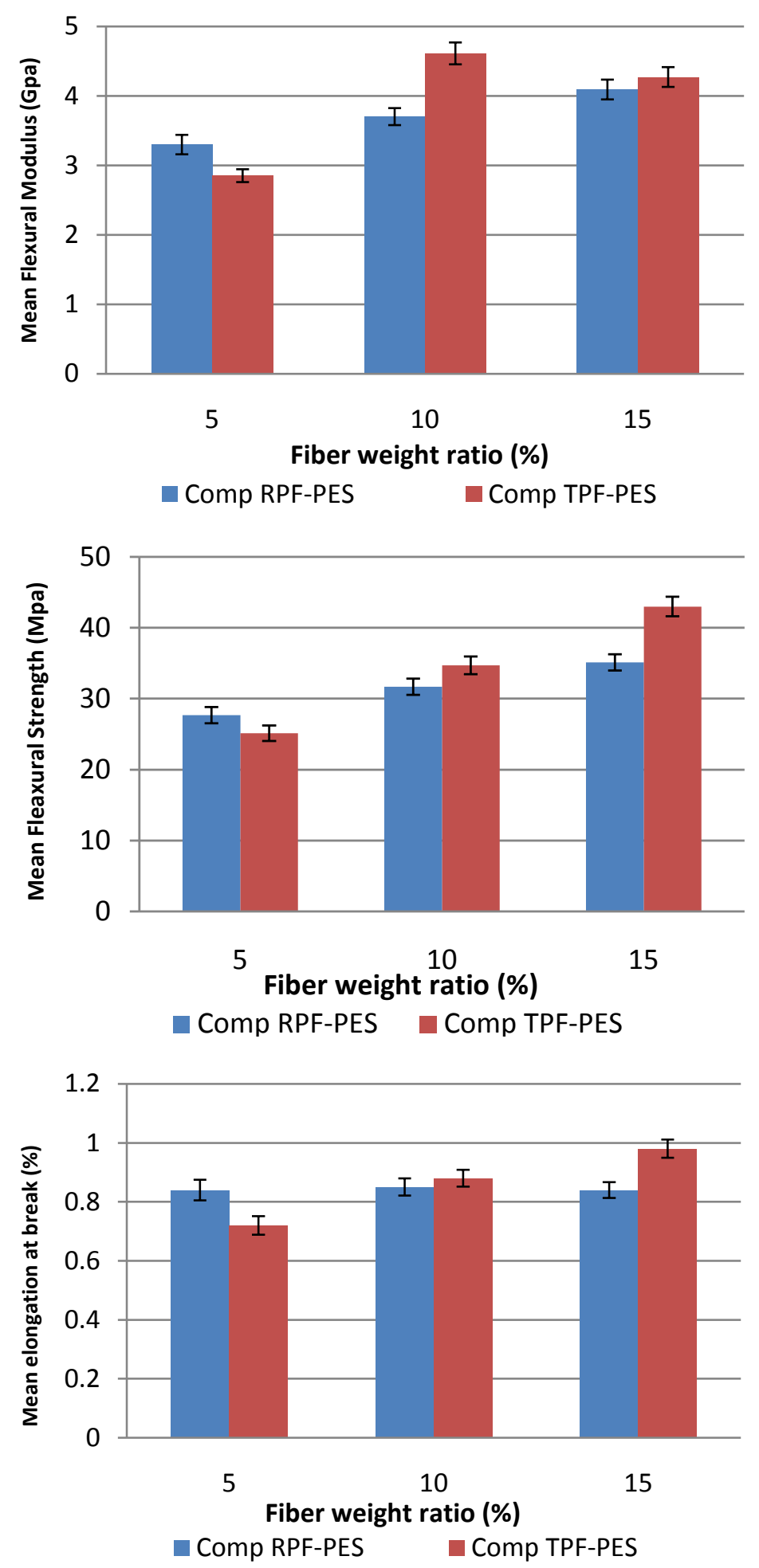

Figure 5. Variation of flexural properties of Posidonia fibers reinforced polyester composites (treated and non treated fibers) with fiber weight ratio.

composites through fiber surface modification. Composites based on the modified fiber surface have, in general, superior mechanical properties to composites containing unmodified fibers. This is primarily a result of im- 
proved adhesion and enhanced polar interactions at the fiber-matrix interfaces. Hence, based on the availability, cheaper and good strength of Posidonia fiber composites investigated in the present study, the composite can certainly be considered as a very promising material to fabrication of lightweight materials used in automobile body building, office furniture packaging industry, partition panels, etc., compared to conventional fibers such as glass and carbon.

\section{References}

[1] Raju, G.U., Gaitonde, V.N. and Kumarappa, S. (2012) Experimental Study on Optimization of Thermal Properties of Groundnut Shell Particle Reinforced Polymer Composites. International Journal of Emerging Sciences, 2, $433-454$.

[2] Joseph, P.V., Marcelo, S. and Rabello, L.H.C. (2002) Environmental Effects on the Degradation Behaviour of Sisal Fibre Reinforced Polypropylene Composites. Composites Science and Technology, 62, 1357-1372. http://dx.doi.org/10.1016/S0266-3538(02)00080-5

[3] Dhakal, H.N., Zhang, Z.Y. and Richardson, M.O.W. (2007) Effect of Water Absorption on the Mechanical Properties of Hemp Fibre Reinforced Unsaturated Polyester Composites. Composites Science and Technology, 67, 1674-1683. http://dx.doi.org/10.1016/j.compscitech.2006.06.019

[4] Paul, S.A., Boudenne, A., Ibos, L., Candau, Y., Joseph, K. and Thomas, S. (2008) Effect of Fiber Loading and Chemical Treatments on Thermophysical Properties of Banana Fiber/Polypropylene Commingled Composite Materials. Composites Part A, 39, 1582-1588. http://dx.doi.org/10.1016/j.compositesa.2008.06.004

[5] Sutharson, B., Rajendran, M., Devadasan, S.R. and Selvam, B. (2012) Effect of Chemical Treatments on Mechanical Properties of Jute Fiber Hybrid Composite Laminates. ARPN Journal of Engineering and Applied Sciences, 7, No. 6.

[6] Herrera-Franco, P.J. and Valadez-González, A. (2005) A Study of the Mechanical Properties of Short Natural-Fiber Reinforced Composites. Composites Part B: Engineering, 36, 597-608. http://dx.doi.org/10.1016/j.compositesb.2005.04.001

[7] Bledzki, A.K. and Gassan, J. (1999) Composites Reinforced with Cellulose Based Fibres. Progress in Polymer Science, 24, 221- 274. http://dx.doi.org/10.1016/S0079-6700(98)00018-5

[8] Bessadok, A., Marais, S., Gouanve, F., Colasse, L., Zimmerlin, I., Roudesli, S. and Me’tayer, M. (2007) Effect of Chemical Treatments of Alfa (Stipa tenacissima) Fibres on Water-Sorption Properties. Composites Science and Technology, 67, 685-697. http://dx.doi.org/10.1016/j.compscitech.2006.04.013

[9] Sydenstricker, T.H.D., et al. (2003) Pull-Out and Other Evaluations in Sisal Reinforced Polyester Biocomposites. Polymer Testing, 22, 375-380. http://dx.doi.org/10.1016/S0142-9418(02)00116-2

[10] Munawar, S., et al. (2008) Effects of Alkali, Mild Steam, and Chitosan Treatments on the Properties of Pineapple, Ramie, and Sansevieria Fiber Bundles. Journal of Wood Science, 54, 28-35. http://dx.doi.org/10.1007/s10086-007-0903-y

[11] Le Troedec, M., Sedan, D., Peyratout, C., Bonnet, J.P., Smith, A., Guinebretiere, R., Gloaguen, V. and Krausz, P. (2008) Influence of Various Chemical Treatments on the Composition and Structure of Hemp Fibres. Composites Part A: Applied Science and Manufacturing, 39, 514-522. http://dx.doi.org/10.1016/j.compositesa.2007.12.001

[12] Andersson, M. and Tillman, A.M. (1989) Acetylation of Jute: Effects on Strength, Rot Resistance, and Hydrophobicity. Journal of Applied Polymer Science, 37, 3437. http://dx.doi.org/10.1002/app.1989.070371214

[13] Aguir, C. (2010) Chemical Modification of Posidonia with Cyclic Anhydrides: Effect on Thermal Stability. Carbohydrate Research, 345, 264-269. http://dx.doi.org/10.1016/j.carres.2009.11.006

[14] Aguir, C. (2006) Experimental Study on Carboxymethylation of Cellulose Extracted from Posidonia oceanica. Journal of Applied Polymer Science, 98, 1808-1816. http://dx.doi.org/10.1002/app.22713

[15] Ncibi, M.C. (2007) Kinetic and Equilibrium Studies of Methylene Blue Biosorption by Posidonia oceanica (L.) Fibres. Journal of Hazardous Materials, 139, 280-285. http://dx.doi.org/10.1016/j.jhazmat.2006.06.029

[16] Khiari, R. (2010) Chemical Composition and Pulping of Date Palm Rachis and Posidonia oceanica-A Comparison with Other Wood and Non-Wood Fibre Sources. Bioresource Technology, 101, 775-780. http://dx.doi.org/10.1016/j.biortech.2009.08.079

[17] Khiari, R. (2011) New Lignocellulosic Fibres-Reinforced Composite Materials: A Step Forward in the Valorisation of the Posidonia Oceanic Balls. Composites Science and Technology, 71, 1867-1872. http://dx.doi.org/10.1016/j.compscitech.2011.08.022

[18] Li, X. (2007) Chemical Treatments of Natural Fiber for Use in Natural Fiber-Reinforced Composites: A Review. Journal of Polymers and the Environment, 15, 25-33. http://dx.doi.org/10.1007/s10924-006-0042-3

[19] Ghali, L., et al. (2011) Effects of Fiber Weight Ratio, Structure and Fiber Modification onto Flexural Properties of 
Luffa-Polyester Composites. Advances in Materials Physics and Chemistry, 1, 78-85.

[20] Ferrero, B., Fombuena, V., Fenollar, O., Boronat, T. and Balart, R. (2014) Development of Natural Fiber-Reinforced Plastics (NFRP) Based on Biobased Polyethylene and Waste Fibers from Posidonia Oceanic Seaweed. Polymer Composites, 36, 1378-1385. http://dx.doi.org/10.1002/pc.23042

[21] Ravi Kumar, N., Ranga Rao, C.H., Raghava Rao, B. and Srinivas, K. (2014) Mechanical Properties of Vakka Fiber Reinforced Polypropylene Composites. International Journal of Innovative Research in Science, Engineering and Technology, 3, 1162-1166.

\section{Submit or recommend next manuscript to SCIRP and we will provide best service for you:}

Accepting pre-submission inquiries through Email, Facebook, Linkedin, Twitter, etc A wide selection of journals (inclusive of 9 subjects, more than 200 journals)

Providing a 24-hour high-quality service

User-friendly online submission system

Fair and swift peer-review system

Efficient typesetting and proofreading procedure

Display of the result of downloads and visits, as well as the number of cited articles

Maximum dissemination of your research work

Submit your manuscript at: http://papersubmission.scirp.org/ 